\title{
Chronic Myeloid Leukemia After Chemoradiotherapy in a Patient with Non-Small Cell Lung Cancer
}

\author{
Sinan DEMIRCIOGLU ${ }^{1}$, Levent KORKMAZ ${ }^{2}$, Seda YILMAZ ${ }^{1}$, Ozlen BEKTAS ${ }^{1}$, \\ Ozcan CENELI ${ }^{1}$, Mehmet ARTAC ${ }^{2}$ \\ ${ }^{1}$ Necmettin Erbakan University, Meram Faculty of Medicine, Department of Hematology \\ ${ }^{2}$ Necmettin Erbakan University, Meram Faculty of Medicine, Department of Oncology, Konya, TURKEY
}

\section{Dear Editor,}

Chronic myeloid leukemia(CML) is a myeloproliferative disease characterized by uncontrolled proliferation of mature and maturing granulocytes. Chronic myeloid leukemia accounts for approximately 15 to 20 percent of leukemias in adults. The incidence is $1-2 / 10000$ per year. ${ }^{1-2}$ There is only one risk factor, which is ionized radiation. ${ }^{3}$ There are some publitions in the literature about CML development after chemotherapy and/or radiotherapy. Here we presented a case that CML occured after chemotherapy concurrent with radiotherapy in non-small cell lung cancer patient.

Sixty year old man who has diagnosed inoperable lung adenocarcinoma in 2013. Carboplatin concurrent with radiotherapy was administered to him. After 2 years follow-up with no progression of disease, the level of leucocyte was started to increase. White blood cell level was 41700/ul, haemoglobin level was $14.3 \mathrm{~g} / \mathrm{dl}$ and platelet level was 239000/ul. Peripheral blood smear suggested chronic myeloid leukemia. Bone marrow aspiration and biopsy was performed. The biopsy was supported chronic phase chronic myeloid leukemia. Cytogenetic analysis showed \%95 translocation $(9 ; 22)$ in 20 metaphasis. BCR-ABL was detected as $60 \%$ IS. Sokal, Hasford and EUTOS risk score was calculated high. Imatinib therapy was started as $400 \mathrm{mg} /$ day. Hematologic response was seen 2 weeks after imatinib treatment. After 3, 6, 12 months, BCR-ABL was detected as
$27 \%$ IS, $1 \%$ IS, and 0.4 IS, respectively. The patient is still being followed as remission for both lung cancer and CML.

Secondary cancers are increasing due to increased survival and new treatment outcomes in cancer treatment. Therapy related acute myeloid leukemia and myelodysplastic syndrome are seen at increasing rates. ${ }^{4}$ However, therapy related CML (tr-CML) is seen rarely. One study showed that tr-CML developed most often after Hodgkin disease. Less reported after breast cancer, chronic lymphocytic leukemia and seminoma. ${ }^{5}$ These diseases may be related to the frequent development of tr-CML, the longer survival of these diseases.

Radiotherapy, chemotherapy and radioactive nuclides used in the treatment cause secondary cancers. ${ }^{4}$ It is well known that topoisomerase-II inhibitors and alkylating agents have leukemogenic potential. ${ }^{5-6}$ Cancer patients with solid tumors developing trCML, used chemotherapies such as cisplatin, bleomycin, cetuximab and 5-fluorouracil. The time range from initial diagnosis of the primary malignancy to tr-CML was about $1-16$ years in various reports..$^{6-10}$ In our case tr-CML developed after 2 years.

Leukoerythroblastic reaction may occur in bone marrow metastasis. If bone marrow metastasis is absent in a patient with leukoerythroblastic reaction, CML should be kept in mind. This case is the first case report of CML development after non-small cell lung cancer treatment in literature. 
The first line of treatment in CML is oral tyrosine kinase inhibitors. The responses are excellent with TKI. As patients with advanced stage CML still have worse prognosis, prevention of disease progression is the most important aspect of CML disease management. ${ }^{11}$ Even in the age of strong TKI, accelerated or blastic phase progression reduce the survival significantly. The risk of this progression can be initially reduced by using the second-generation TKI nilotinib and dasatinib. High Sokal risk and complex karyotype in which there is a tendency to use more powerful TKI. Likewise, also in young and low-risk patients with treatment discontinuation future drug candidates may start with second-generation. However, heterogeneous presentation and course of CML, individual characteristics of patients, compliance and preferences, comorbidities, different toxicity profile of the drug, physician-clinic center experience are taken into account in the selection of first-line treatment in the new diagnosis CML. ${ }^{12-14}$ Expert opinion on CML treatment; Low-risk chronic phase imatinib $400 \mathrm{mg}$ / day in CML, and second-generation TKIs (dastinib or nilotinib) which are stronger in patients with high Sokal risk. ${ }^{15}$ Since our patient has a high Sokal risk score and is a secondary CML, it seems more appropriate to start treatment with second-generation TKI. It is more appropriate to start nilotinib if the administration of dasatinib leads to the development of pleural effusion because the patient has lung cancer. However, due to the repayment conditions in our country, we started imatinib as the first line treatment.
5. Aguiar RC. Therapy-related chronic myeloid leukemia: an epidemiological, clinical and pathogenetic appraisal. Leuk Lymphoma 29: 17-26, 1998.

6. Waller CF, Fetscher S, Lange W. Treatment-related chronic myelogenous leukemia. Ann Hematol 78: 341-354, 1999.

7. Porta C, Casagranda I, Semino G, et al. Chronic myeloid leukemia following cyclophosphamide-containing chemotherapy in a breast cancer patient. Haematologica 78: 56-57, 1993.

8. Buxhofer-Ausch V, Hinterberger-Fischer M, Hinterberger W. Bcr-abl positive blast crisis of chronic myeloid leukemia emerging in a case of metastatic colorectal cancer 3 months after completion of an 8-month course of cetuximab and irinotecan. Eur J Haematol 76: 447-448, 2006.

9. Gokel Y, Paydas S. Chronic myeloid leukemia in a patient with colon adenocarcinoma. Haematologia (Budap) 32: 501503, 2002.

10. Nakamura $\mathrm{H}$, Inokuchi $\mathrm{K}$, Hanawa $\mathrm{H}$, et al. A case of chronic myeloid leukemia with minor bcr-abl transcript following fluorouracil therapy for esophageal carcinoma. Ann Hematol 79: 396-401, 2000.

11. Baccarani M, Deininger MW, Rosti G, et al. European LeukemiaNet recommendations for the management of chronic myeloid leukemia: 2013. Blood 122: 872-884, 2013.

12. Baccarani M, Cortes J, Pane F, et al. Chronic myeloid leukemia: an update of concepts and management recommendations of European LeukemiaNet. J Clin Oncol 27: 6041-6451, 2009.

13. Kantarjian $\mathrm{H}$, Shah NP, Hochhaus A, et al. Dasatinib versus imatinib in newly diagnosed chronic-phase chronic myeloid leukemia. N Engl J Med 362: 2260-2270, 2010.

14. Saglio G, Kim DW, Issaragrisil S, et al. Nilotinib versus imatinib for newly diagnosed chronic myeloid leukemia. N Engl J Med 362: 2251-2259, 2010.

15. Haznedaroglu IC. Current concerns of undertreatment and overtreatment in chronic myeloid leukemia based on European LeukemiaNet 2013 recommendations. Expert Opin Pharmacother 14: 2005-2010, 2013.

\section{REFERENCES}

1. Sant M, Allemani C, Tereanu C, et al. Incidence of hematologic malignancies in Europe by morphologic subtype: results of the HAEMACARE project. Blood 116: 3724-3734, 2010.

2. Smith A, Howell D, Patmore R, et al. Incidence of haematological malignancy by sub-type: a report from the Haematological Malignancy Research Network. Br J Cancer 105: 1684-1692, 2010.

3. Faderl S, Talpaz M, Estrov Z, et al. The biology of chronic myeloid leukemia. N Engl J Med 341: 164-172, 1999.

4. Levine EG, Bloomfield CD. Leukemias and myelodysplastic syndromes secondary to drug, radiation, and environmental exposure. Semin Oncol 19: 47-84, 1992.

\section{Correspondence:}

Dr. Sinan DEMIRCIOGLU

Necmettin Erbakan Üniversitesi Meram Tip Fakültesi

Hematoloji Anabilim Dali

42080 Meram,

KONYA / TURKEY

Tel: (+90-332) 2237869
Fax: (+90-332) 2237938
e-mail: sinandemircioglumd@gmail.com 